\title{
El liberalismo de Friedrich A. Hayek y Judith N. Shklar: una comparación ${ }^{1}$
}

\section{The Liberalism of Friedrich A. Hayek and Judith N. Shklar: a Comparison}

\author{
Paloma De la Nuez Sánchez-Cascado² \\ Universidad Rey Juan Carlos (España)
}

Recibido: 03-08-18

Aprobado: 24-04-18

\section{Resumen}

La comparación entre el pensamiento político de dos grandes liberales, Judith N. Shklar y Friedrich A. Hayek, además de constituir una empresa intelectual sumamente estimulante, resulta muy útil para comprender la evolución del pensamiento político liberal en el siglo XX.

Shklar, cuyo reconocimiento internacional está creciendo sin cesar en los últimos años, escribe que el liberalismo se hace contra el totalitarismo como doctrina política que pone por encima de cualquier otro valor la libertad, principio también fundamental en la obra de F. A. Hayek. Por eso, a pesar de que la profesora de Harvard pensaba que su liberalismo era muy diferente al del economista vienés creemos, sin embargo, que existen más semejanzas de las que se podrían deducir a primera vista. Entre otras cosas porque ambos pensadores experimentaron la fragilidad de la libertad y de la democracia en la época que les tocó vivir y decidieron dedicar su trabajo intelectual a estudiar las condiciones en las que se preserva la libertad personal.

En ese sentido, en un mundo en el que la democracia liberal sufre de nuevo duros embates, su obra es también de gran actualidad.

Palabras-clave: Shklar, Hayek, liberalismo, libertad, injusticia.

\footnotetext{
${ }^{1}$ Este artículo se enmarca en el Proyecto de investigación: Jueces en Democracia. La filosofía política de la Corte Interamericana de Derechos Humanos. Proyecto financiado por el Ministerio de Economía, Industria y Competitividad. Referencia: DER2016-79805-P (AEI/FEDER, UE).

22(paloma.delanuez@urjc.es) Profesora del Departamento de Ciencias de la educación en la Universidad Rey Juan Carlos donde enseña Historia de las ideas políticas. Sus líneas de investigación son las siguientes: Historia de las Ideas Políticas, Teoría Política Contemporánea, el liberalismo en la segunda mitad del siglo XX, la Ilustración y los orígenes del liberalismo, emociones políticas e Historia de las mujeres. Es autora de varias publicaciones entre las que destacan, Turgot, el último ilustrado (Unión Editorial, Madrid, 2010) y La política de la libertad. Estudio del pensamiento político de F.A. Hayek, $2^{\mathrm{a}}$ edición, Unión Editorial, Madrid, 2010).
} 


\section{Abstract}

AThe comparison between the political thought of two great liberals, Judith N. Shklar and Friedrich A. Hayek, as well as constituting a highly-stimulating and intellectual enterprise, is very useful in understanding the evolution of liberal political thought in the 20th century.

Shklar, whose international recognition has steadily increased in recent years, argues that liberalism goes against totalitarianism as a political doctrine that places freedom above any other value. This fundamental principle can also be seen in the work of F. A. Hayek. This is why, despite the fact that the Harvard professor thought that her idea of liberalism was very different from that of the Viennese economist, we believe that there are more similarities than could be inferred at first glance. Among other things, because both thinkers experienced the fragility of freedom and democracy during the era in which they lived and thus decided to devote their intellectual work to studying the conditions in which personal freedom is preserved.

Thus, in a world in which liberal democracy is once again coming under fierce attack, this work is of great relevance.

Key-words: Shklar, Hayek, liberalism, freedom, injustice.

\section{La crítica de Judith Shklar al liberalismo hayekiano}

\subsection{El liberalismo de Hayek es conservador}

Judith N. Shklar conocía bien el pensamiento del pensador austriaco y se refiere a su obra en varios de sus escritos; desde su tesis doctoral de 1957, After Utopia. The Decline of Political Faith, pasando por su libro preferido: Legalism. Law, Morals and Political trials (1964), hasta Los rostros de la injusticia (1990). Las numerosas referencias que hace nuestra autora a Camino de servidumbre (1944), Individualismo y orden económico (1948), La contrarevolución de la ciencia (1952), El capitalismo y los historiadores (1954), Los Fundamentos de la libertad (1960), El socialismo y los intelectuales (1967) o Derecho, Legislación y libertad (1973-79), revelan su interés por F.A. Hayek sobre el que escribió que, a pesar de sus discrepancias, era coherente y honesto en sus planteamientos. Unos planteamientos -escribe- que poseían tal capacidad de seducción que le hacían difícil sustraerse a sus argumentos ${ }^{3}$.

${ }^{3}$ Véase, Legalism. Law, Morals and Political Trials, Harvard University Press, 1986, p.23. Sin embargo, no parece que ocurra lo mismo en sentido contrario y no hemos encontrado referencias a Shklar en las principales obras de Hayek.

Araucaria. Revista Iberoamericana de Filosofia, Política, Humanidades y Relaciones Internacionales, año $21, \mathrm{n}^{\circ} 41$. Primer semestre de 2019. Pp. 37-60. ISSN 1575-6823 e-ISSN 2340-2199 doi: 10.12795/araucaria.2019.i41.02 
Pero a pesar de esa atracción, Shklar tenía muy claro que Hayek defendía un tipo de liberalismo distinto del suyo y escribió en After Utopia y en Legalism que el liberalismo que defendían los miembros de la sociedad Mont Pèlerin (fundada por el economista vienés), así como el de los autores agrupados alrededor de la revista Ordo, era profundamente restrictivo y conservador y, por lo tanto, muy alejado del suyo, a pesar de que el autor austriaco se había tomado la molestia de escribir "Por qué no soy conservador" en el Epílogo a Los fundamentos de la libertad ${ }^{4}$.

La profesora de Harvard creía que desde la Primera Guerra Mundial el liberalismo se había ido haciendo cada vez más fatalista sucumbiendo al espíritu de la desesperación en vez de combatirlo, por eso no dudaba en denominarlo "liberalismo de la derrota". Un liberalismo más influido por las ideas de Edmund Burke que por las esperanzas de los ilustrados del siglo XVIII; un liberalismo desencantado con el desarrollo y la evolución de la historia moderna, sobre todo del racionalismo, cuyo historicismo y determinismo económico conducen al quietismo político. En el caso de Hayek, su fatalismo se basa, según ella, en que el racionalismo es un state of mind que lo invade todo y que no se puede alterar; que crea no sólo un cierto tipo de sociedad sino un cierto tipo de persona, mientras que el liberalismo de ella desafía el status quo porque quiere cambiar las cosas, sobre todo a lo que a las injusticias se refiere ${ }^{5}$.

La autora americana hizo de la justicia o, más bien de la injusticia, uno de los temas fundamentales de su obra y precisamente es la visión que Hayek tiene de la justicia lo que les separa por encima de todo. En su libro Legalism, Shklar cuestiona la visión liberal tradicional del gobierno de la ley porque asume una teoría de la justicia que da por hecho la existencia de una racionalidad neta y uniforme en todos los seres humanos que poco o nada tiene que ver con la realidad en la que la irracionalidad y la pluralidad son la norma.

Se trata de un liberalismo que "se cuelga" del legalismo como si la ley no tuviera nada que ver con la política y solo existiera para limitarla cuando

${ }^{4}$ Shklar lleva a cabo un análisis de este grupo y sus ideas en su libro After Utopia. The Decline of Political Faith, Princeton University Press, New Jersey, 1969, en el capítulo dedicado a The end of radicalism, p.219 y ss. El célebre texto de Hayek al que se hace referencia en el párrafo se encuentra en Los fundamentos de la libertad, Unión Editorial, Madrid, 1998, p. 506 y ss.

5 "The liberalism of defeat", en After Utopia, the Decline of Political Faith, Princeton Legacy Library, New Jersey, 1969, p. 236. Sin embargo, a pesar de que en este momento creyera que el liberalismo del austriaco tenía un carácter fatalista y conservador, más adelante escribiría que Hayek caía en ese optimismo de cierto tipo de liberalismo (señaladamente el de J. Stuart Mill) por su tesis de que el rule of law genera un orden espontáneo de tipo evolutivo y porque existe una selección natural de leyes y tradiciones que hacen que el mundo se mueva siempre hacia niveles superiores de civilización (aunque ella dice que no ofrece ninguna prueba histórica de sus teorías y que sus asunciones sobre la ignorancia humana y sus consecuencias políticas son infalsificables). En el fondo -afirma- se trata de una fe ciega en el progreso humano y en el progreso moral y por eso añade (contradiciendo su tesis anterior) que "Hayek is quite right in refusing to think of himself as a conservative". (Véase, S. Hoffmann, ed., Political Thought and Political Thinkers, The University of Chicago Press, 1998, p. 28).

Araucaria. Revista Iberoamericana de Filosofia, Política, Humanidades y Relaciones Internacionales, año $21, \mathrm{n}^{\circ} 41$. Primer semestre de 2019. Pp. 37-60. ISSN 1575-6823 e-ISSN 2340-2199 doi: 10.12795/araucaria.2019.i41.02 
es evidente que no existe al margen de las ideologías, sino que se encarna en la política y en la historia y expresa valores políticos. Por eso, también en Los rostros de la injusticia critica a Hayek por hacer ideología: "the ideology of the rule of law". Es decir, por creer que la solución, "the miracle of liberalism", es el gobierno de le ley como si la ley fuera estrictamente neutral ${ }^{6}$. Esa gran ideología a la que habría contribuido tanto el pensador austriaco, incluye una teoría epistemológica, psicológica, económica, política e histórica, aunque en realidad sería la política económica lo verdaderamente importante, como lo es siempre para los defensores del capitalismo. Es decir, al final la relevancia del imperio de la ley estriba en que favorece la economía de mercado, opina Shklar.

En Los rostros de la injusticia, insiste nuestra autora en que para Hayek el rule of law es necesario por la irreductible ignorancia de los seres humanos. Todo su liberalismo se basaría en una teoría del conocimiento que parte de la ignorancia y la falibilidad humana, sobre todo en el ámbito del mercado, lo que implica que los individuos deben guiar su conducta de acuerdo con reglas. Pero la ignorancia de él - escribe- no es la del escepticismo filosófico y general que sostenía, por ejemplo, su admirado Montaigne, sino que su escepticismo es altamente selectivo porque limita nuestra ignorancia a nuestro conocimiento de las transacciones del mercado donde estamos abandonados a la oscuridad, aunque si esto fuera cierto no haríamos proyectos de vida y caeríamos en la parálisis, afirma Shklar ${ }^{7}$.

Así, en la versión hayekiana, la ley adquiere el carácter de una necesidad natural que prevalece y a la que la gente se ajusta espontáneamente de modo que se acaba identificando la seguridad con la libertad. No es que no le preocupe la coacción, pero la coacción hayekiana es la que ocurre cuando una persona es obligada por un mandato directo a hacer algo que sirve, no a sus fines sino a los fines de otro, y la fuente principal de esa coacción suele ser el gobierno. De nuevo, para Hayek, el rule of law no sería necesario porque haya peligro de opresión y persecución ("general and impersonal rules are not there to protect rights") sino porque sirve al orden de mercado. La legalidad liberal que él defiende no es tanto contra la represión que pueda imponer una tiranía, por ejemplo, sino contra la arbitrariedad; como si lo único importante fuera que las normas dejen de ser seguras y predecibles. Por eso piensa Shklar que la prioridad de Hayek ha sido mantener la estabilidad y el orden social ${ }^{8}$.

Además, a ella no le acaba de convencer esa diferencia que él hace entre las leyes generales y abstractas (nomos), el marco jurídico que corresponde a

\footnotetext{
${ }^{6}$ Legalism, op. cit., p. 23.

${ }^{7}$ Los rostros de la injusticia, Herder, Barcelona, 2013, p. 132.

8 Aunque, contradiciéndose de nuevo respecto a lo que había escrito sobre este asunto, en el sentido de que este rule of law existe únicamente para prevenir la ineficiencia, la irregularidad o la irracionalidad, escribirá en Political Thought and Political Thinkers que también la legalidad hayekiana lucha contra la arbitrariedad y la opresión (Political Thought and Political Thinkers, op. cit., p. 28).
}

Araucaria. Revista Iberoamericana de Filosofia, Política, Humanidades y Relaciones Internacionales, año $21, \mathrm{n}^{\circ} 41$ Primer semestre de 2019. Pp. 37-60. ISSN 1575-6823 e-ISSN 2340-2199 doi: 10.12795/araucaria.2019.i41.02 
una sociedad abierta, y los mandatos (thesis) que rigen en las organizaciones, puesto que hay mandatos que son generales y leyes generales que pueden ser muy coercitivas. Tampoco le convence su tesis de que es sobre un orden espontáneo sobre el que el resto de la sociedad descansa, y la implicación de que la justicia es imposible en otras circunstancias. Asimismo, la propia ley, al refinarse y hacerse más compleja, puede crear sus propias injusticias.

Shklar no podía compartir un legalismo apolítico tan alejado de la realidad que dejaba fuera, además, algo tan importante para ella como era la vida emocional. Nuestras creencias y la ideología determinan nuestro sentido de la justicia, pero el discurso del liberalismo dominante sobre el derecho es un discurso formal, procedimental, abstracto y ahistórico que resulta claramente inadecuado e insuficiente para dar cuenta de la injusticia, del sentimiento y la experiencia de las víctimas, por lo que acaba siendo una justicia incompleta.

Por último, se puede luchar perfectamente contra la injusticia sin necesidad de tener una definición clara y distinta de lo que es la justicia. No hace falta creer en una teoría ideal; todos hemos experimentado alguna vez lo que es sentir que algo es injusto y por eso somos capaces de reconocer las injusticias. Tenemos un sentido de la justicia previo a cualquier reflexión; un sentido moral común y universal que nos impone el deber de escuchar a las víctimas y que nos ayuda a decidir si se ha sufrido o no una injusticia.

\subsection{En el mercado sí existe la injusticia}

Para Hayek, la ley sirve básicamente para limitar la coacción arbitraria. Sin embargo, cuando el economista austriaco habla de coacción se refiere únicamente a la del Estado, puesto que él no parece contemplar la posibilidad de que haya coacción en el orden espontáneo que es el mercado (siempre y cuando se respete la ley, no se use la violencia ni se cometa fraude y engaño). El mercado no tiene conciencia ni voluntad; no decide nada, por lo que no es responsable de la buena o mala suerte de los individuos que participan en él y no se le puede acusar, por lo tanto, de ser injusto. No obstante, de acuerdo con la interpretación de Shklar, esta visión del mercado, unida a su teoría convencional de la justicia, le impediría a Hayek preocuparse por los que se sienten injustamente tratados y sufren por ello, ya que sólo sería injusto lo que infringe la justicia normal. Sin embargo, ella cree que puede ocurrir que procedimientos justos perpetúen injusticias. Está claro, por ejemplo, que puede haber discriminación social, aunque no la haya legal.

Por otro lado, ella no niega que el mercado sea eficiente ni que la propiedad privada sea necesaria, pero afirma que también tiene efectos perversos que incluso el economista de la Escuela Austriaca no puede negar. Hay víctimas del mercado; individuos que se sienten injustamente tratados por muy libre 
y competitivo que éste sea (o precisamente por eso). Lo que ocurre es que él asume que hay cosas inevitables que hay que aceptar. La injusticia es una parte inherente a la sociedad espontánea y algunas expectativas se frustrarán siempre.

Es precisamente esa percepción del asunto lo que ella no comparte, esa visión del mercado que ofrece Hayek en El espejismo de la justicia social, como si se tratara de una fuerza impersonal de la naturaleza a la que no se le puede exigir responsabilidades por la desgracia o la mala suerte de nadie, ya que en el reino de la necesidad es absurdo quejarse de la injusticia, algo parecido a lo que ocurre cuando se produce un terremoto. Se trata de una desventura y no de una injusticia9.

Shklar reconoce que no es fácil discernir entre lo que es injusticia y lo que es desventura (además, lo que se percibe como desventura o como injusticia cambia con el tiempo), pero existen situaciones que son resultado de la injusticia activa o pasiva y que, aunque sean difíciles o costosas de corregir, no son situaciones imposibles. Por eso, es importante el que algo se considere una desventura o una injusticia (decisión que tiene mucho que ver con la ideología), ya que si lo que se considera desventura pasa a ser contemplado como injusticia es más probable que se decida actuar. Por ejemplo, hay catástrofes naturales que se pueden prever o cuyos efectos se pueden paliar mediante decisiones políticas de las que alguien se tendrá que hacer responsable, aunque también reconoce que hay desventuras a las que hay que resignarse.

Por otro lado, ella sí da margen a la intervención del Estado para paliar las injusticias del mercado porque en su pensamiento político la justicia está ligada a la igualdad. Entre las fuentes de la injusticia y de la opresión están las diferencias de poder entre unos ciudadanos y otros, y esas diferencias se basan muy a menudo en la desigualdad económica y social que, aunque insiste en que son inevitables, se pueden reducir y atemperar. Las desigualdades extremas son dañinas y crean condiciones favorables para el abuso porque provocan que los que están debajo de la jerarquía social sufran la crueldad -el peor de todos los males- por parte de los de arriba (no se trata con crueldad a los que se considera iguales), lo que les conmina a guardar silencio, además de aislarlos unos de

\footnotetext{
${ }^{9}$ Véase Los rostros de la injusticia, op. cit, p. 135. Shklar reconoce que el economista vienés "no endulza la píldora" y que no evade las consecuencias de su tesis que afirma con claridad y heroísmo, lo que para ella es meritorio por único (Ibidem, p. 131). Pero seguramente compartiría la afirmación de I.M. Young de que hay injusticias cuya causa es social, producto del sistema y no de la mala suerte, porque existe en nuestras sociedades de mercado una injusticia estructural a la que contribuimos todos sin haberla buscado o incluso sin ser en absoluto conscientes, lo que no quiere decir que no debamos hacer nada porque políticamente sí somos responsables. Véase Political Responsability and Structural Injustice, Lindley Lecture, Universidad de Kansas, 5 mayo 2003, p. 3.

Por otro lado, la tesis de Shklar recuerda también a la de E. Garzón Valdés que distingue entre calamidades y catástrofes, así como a algunas de las tesis de C. Thiebaut sobre el daño y la injusticia. Véase, C. Thiebaut, "Mal, daño y justicia", Azafea. Revista de filosofia, n.7, pp.15-46, Salamanca, 2005 .
} 
otros. Como también sostenía uno de sus autores predilectos, J. J. Rousseau, ella también cree que la desigualdad tiene efectos psicológicos destructivos sobre la libertad de los individuos ${ }^{10}$.

En Los rostros de la injusticia ofrece un ejemplo concreto. Plantea si el desempleo es una desventura o una injusticia y pone el ejemplo del trabajo y el derecho a la ciudadanía en los Estados Unidos. En su país de adopción, aunque se tengan todos los derechos de participación política, si un americano no tiene trabajo sufre el estigma de no ser un ciudadano completo y pierde el respeto de los demás a la vez que su dignidad. Por eso, Shklar considera justo que el Estado ayude a la gente a ganarse la vida con una especie de "right to earn" promovido a través de políticas públicas, sobre todo de alcance local, o incluso con un salario mínimo. Hay derechos que requieren que el gobierno haga algo y hay muchas cosas que el gobierno puede hacer; de hecho, no hacer nada supone ser "pasivamente injusto". Las instancias públicas deben ayudarnos y protegernos porque también existe el miedo en el mercado; en este caso, el miedo al desempleo ${ }^{11}$.

La profesora de Harvard se resiste a aceptar un gobierno inactivo que abandone a su suerte a los más débiles y vulnerables, un sistema pasivamente injusto. No es el origen del daño lo que cuenta; sea este el que sea, hay que aliviar el sufrimiento cualquiera que sea su causa (también hay injusticias por negligencia de ciudadanos privados). Es injusto negar la ayuda, es injusto no hacer nada. La democracia no debe ignorar la forma en que los individuos perciben la injusticia y la vulneración de sus derechos, y lo que debe hacer un ciudadano en una democracia es protestar. La alternativa es complacencia y eso es injusto siempre.

De todos modos, Shklar reconoce que Hayek "no culpa a los pobres de su pobreza" e incluso sugiere que algunas personas deben ser ayudadas (aunque no por el gobierno central que se vería tentado a meter sus manos en el mercado), pero parece creer que esas personas están mejor de lo que se piensa y que se ha hecho ya por ellos todo lo que se podía hacer. Además, el economista vienés opina que si fuera el Estado el que distribuyese la riqueza en función de lo que merece cada uno (en el supuesto de que fuese posible saberlo), aceptaríamos peor nuestra suerte que si ésta depende de algo tan azaroso como el mercado. Sin embargo, Shklar opina que no, que es al revés, que la gente lo que quiere es superar la naturaleza precisamente mediante la ingeniería social y la tecnología ${ }^{12}$.

${ }_{10}$ Shklar recuerda en Liberalism of Fear que las personas con poder económico también pueden intimidar a través del uso de su capacidad de contratar, pagar, despedir o determinar los precios (Liberalism of Fear, en N.L. Rosenblum, ed., Liberalism and the Moral Life, Harvard University Press, 1989, p.31).

11 Véase American Citizenship: The Quest for Inclusion, The Tanner Lectures on Human Values, University of Utah, 1989. p. 438.

${ }^{12}$ Los rostros de la injusticia, op. cit., p. 137 y After Utopia. The Decline of Political Faith, op. cit., p. 251.

Araucaria. Revista Iberoamericana de Filosofia, Politica, Humanidades y Relaciones Internacionales, año $21, \mathrm{n}^{\circ} 41$. Primer semestre de 2019. Pp. 37-60. ISSN 1575-6823 e-ISSN 2340-2199 doi: 10.12795/araucaria.2019.i41.02 
En definitiva, Hayek, como ya antes David Hume o Adam Smith, tendría una visión de la justicia como evitación de la violencia que para ella resulta claramente insuficiente. Una visión estrecha reducida al mantenimiento de la paz y de la propiedad.

\subsection{La libertad negativa no implica la pasividad del Estado}

Lo que Shklar no puede poner en duda es que también para Hayek el liberalismo es lo opuesto al totalitarismo. La libertad es el principio fundamental y coincide con ella en que el liberalismo tiene que ofrecer y asegurar las condiciones políticas para su ejercicio. Lo que ocurre es que, aunque podría pensarse que la autora americana por su desconfianza hacia el poder del Estado coincidiría con el profesor austriaco en la defensa de la libertad negativa, no es así. Shklar reconoce que no le gusta hacer concesiones a la libertad positiva, pero que las dos libertades a las que se refería I. Berlin no tienen por qué estar en conflicto ni hay por qué elegir entre una y otra; al contrario: ambas se apoyan mutuamente ${ }^{13}$.

Desde su punto de vista, la libertad negativa sería la libertad más simple, la condición para libertades más activas y amplias y, a diferencia de Hayek, no significa necesariamente que el gobierno tenga que ser pasivo o intervenir lo menos posible. Al contrario, exige voluntad política para estas dos cosas: para proteger a las minorías y para educar al pueblo. $\mathrm{Y}$ a las minorías se las protege otorgándoles la misma protección de las leyes y atendiendo a sus demandas (y pone como ejemplo a los ciudadanos negros en los Estados Unidos). Además, resulta difícil imaginar cómo se podría combatir la crueldad, para ella el mayor de todos los males, con la libertad negativa entendida sólo como prohibición de interferencias por parte del Estado.

Respecto a la parte positiva de su concepto de libertad, esta reside sobre todo en la lucha por los derechos. La libertad positiva supone un proceso sin fin de reclamación de derechos y libertades. El ciudadano liberal pelea por sus derechos que nunca serán lo suficientemente extendidos y respetados, por lo que no ser un ciudadano activo también es injusto. Precisamente, es la cultura política americana que Shklar admira, estudia y conoce bien, la que identifica libertad con derechos. Se trata de una cultura legalista en la que los jueces y los tribunales han sido en muchas ocasiones los que han reconocido y protegido los derechos de las minorías (y no las masas o las asambleas democráticas precisamente).

La libertad consiste no solo en tomar sin miedo decisiones sobre la propia vida (que cada uno decida cómo quiere usar su libertad según sus principios y

${ }^{13}$ Véase, "Positive Liberty, Negative Liberty in the United States, en S. Hoffmann, ed., Redeming American Political Thought, The University of Chicago Press, 1998, p. 126.

Araucaria. Revista Iberoamericana de Filosofía, Política, Humanidades y Relaciones Internacionales, año $21, \mathrm{n}^{\circ} 41$. Primer semestre de 2019. Pp. 37-60. ISSN 1575-6823 e-ISSN 2340-2199 doi: 10.12795/araucaria.2019.i41.02 
valores), sino también en tener opciones. En la vida diaria, la libertad depende del número de alternativas genuinas de acción abiertas al individuo, lo que en el caso de Shklar puede suponer "romper las barreras excluyentes" a través de actuaciones positivas del Estado; sin embargo, cree que la separación tajante entre lo público y lo privado que hace Hayek, haría de esta acción del Estado algo mucho menos legítimo. Ella, en cambio, acepta una separación entre los dos ámbitos más flexible.

Por último, su idea de libertad va también ligada a la defensa de una ciudadanía activa y vigilante que no se conforma con el status quo. Por eso mismo, participar y votar no son condiciones de la libertad, son la libertad misma y una forma permanente de hacer política ${ }^{14}$.

\section{Los dos liberalismos:}

Como hemos visto, es la propia Shklar la que se ocupa de señalar las importantes diferencias que existen entre su liberalismo y el de Hayek. No obstante, creemos que existen también semejanzas que explicaremos a continuación, indicando de paso otras discrepancias que no señaló la autora americana.

\subsection{La renovación del liberalismo y sus fundamentos}

La vida de ambos autores estuvo marcada por la experiencia totalitaria, aunque de modo más directo y trágico en el caso de Shklar que describe en su único escrito autobiográfico, A Life of Learning (1989), cómo su vida y la de su familia estuvo completamente dominada por la política. La crisis de la democracia liberal, el ascenso del fascismo y del comunismo, la violencia y la guerra les hizo comprender que "el ethos individualista que sostiene los derechos y libertades" es muy frágil y decidieron dedicar su trabajo intelectual a recuperar - revitalizado y renovado- ese liberalismo que la autora considera se mostraba inseguro sobre su identidad y fundamentos morales ${ }^{15}$.

En ese afán por la renovación del pensamiento liberal, ninguno de los dos profesores se comprometerá con partido o movimiento político alguno, sino que preferirán confiar en el poder de las ideas. Ella, como profesora en Harvard de Teoría Política y él como profesor en varias universidades de Europa y de Estados Unidos, interesados siempre por el pensamiento político, acudirán a la historia de las ideas en busca de autores y referencias que iluminen sus aportaciones teóricas. Tanto uno como otro revelan en sus escritos un gran

${ }^{14}$ Véase, Redeming American Political Thought, op. cit., p. 11 y ss.

15 Véase A Life of Learning, ACLS Occasional Paper, N.9, 26 de abril de 1989.

Araucaria. Revista Iberoamericana de Filosofia, Politica, Humanidades y Relaciones Internacionales, año $21, \mathrm{n}^{\circ} 41$. Primer semestre de 2019. Pp. 37-60. ISSN 1575-6823 e-ISSN 2340-2199 doi: 10.12795/araucaria.2019.i41.02 
conocimiento de la historia del pensamiento político que -como apunta la autora americana- nos ayuda a pensar y nos enseña a entender el mundo que nos rodea.

En ese sentido, convencidos de que las ideología tienen consecuencias, contribuyeron ambos a la historia de las ideas desde perspectivas diferentes. En el caso de Shklar, una perspectiva muy original que incide sobre todo en el estudio psicológico de las ideologías, ya que considera que un mayor interés en la psicología puede conducir a un modo más refinado y detallado de analizar la historia de las ideas políticas. Las fuerzas psicológicas tienen un inmenso poder y "las ideas solo se hacen fuerzas sociales poderosas cuando se corresponden con una necesidad psicológica ampliamente compartida". En el caso de Hayek, su dedicación a la historia de las ideas no sólo económicas, sino políticas, ha sido también una de sus mayores ocupaciones y aportaciones ${ }^{16}$.

Sin embargo, a pesar de la calidad e interés de sus trabajos, los dos pensadores estuvieron -sobre todo en un primer momento-, fuera de las corrientes dominantes de sus respectivas disciplinas y en cierto modo eran considerados unos "outsiders". Shklar reconocía que hacía una teoría política muy libre y no se plegaba a las modas intelectuales del momento, como tampoco lo hacía Hayek. Los dos rechazaban la especialización y la sistematización de un determinado tipo de ciencia política. No apreciaban el cientificismo ni el positivismo, ni las propuestas de la Postmodernidad con su relativismo y subjetivismo. Consideraban que la educación para la libertad pasaba por la recuperación de una educación humanista que evitase "la barbarie del especialista". El economista vienés criticaba el exceso de especialización que se daba, sobre todo en las ciencias humanas y defendía "una buena cultura general", una educación mucho más humanista para el científico social. Hayek escribe que hay sabiduría en nuestros tesoros culturales como es la gran literatura y que había que sentirse orgulloso de la estrecha relación que había habido siempre entre las ciencias sociales y la filosofía. En eso no podría haber estado más de acuerdo con J. Shklar que acude constantemente al arte y a la literatura (teatro, novela o poesía) en busca de referencias que cubren las lagunas de la filosofía y la teoría política y ayudan a explicar sus tesis de un modo parecido a como también ocurre a veces con R. Rorty o M. Nussbaum ${ }^{17}$.

De todos modos, las aspiraciones teóricas de Hayek son más elevadas que las de Shklar. Como ella misma reconoce, el liberalismo hayekiano pretende

${ }^{16}$ Sobre las necesidades psicológicas permanentes de los hombres, véase J. Shkar, ed., Political Theory and Ideology, Harvard University Press, 1966, p. 16.: "A greater interest in psycology may lead to far more refined and detailed ways of analyzing the history of ideas", op. cit., p. 19.

Por su parte, Hayek, escribe en The Counter-Revolution of Science, Studies on the Abuse of Reason que la historia de las ideas es muy útil porque "it may serve the purposes of a psychoanalytical operations by bringing out to the surface unconscious elements which determine our reasoning". (The Counter-Revolution of Science, Studies on the Abuse of Reason, The FreePress, Illinois, 1952, p. 191).

${ }^{17}$ Véase para Hayek, "El dilema de la especialización" en Estudios de filosofia, política y economía, Unión Editorial, Madrid, 2007, p. 185 y ss. 
fundamentarse sobre toda una epistemología, psicología, filosofía y, sobre todo, apoyarse en una teoría económica irrebatible, mientras que el de ella lo hace sobre algo tan subjetivo, ambiguo y complicado como es una emoción; en este caso, el miedo. Quizás por eso en el liberalismo de ella apenas hay interés por las cuestiones económicas, aunque da por hecho que sin propiedad privada y mercado, no hay libertad. Pero no es ese aspecto del pensamiento liberal lo que le interesa. No solo no se ocupa de cuestiones económicas, lo que para él sería un fallo muy grave, sino más bien de cuestiones políticas y sobre todo morales.

Shklar quiere entender el comportamiento humano y por eso profundiza en la dimensión psicológica de la política y, aunque sabe que se trata de una cuestión muy complicada, aspira a comprender la psicología moral del liberalismo, la del compromiso liberal para así poder averiguar cuál debe ser el carácter necesario para mantener las condiciones de la libertad política. Para esa tarea y, como decíamos más arriba, el arte y la literatura la ayudarán a comprender mejor la vida emocional de las gentes apartándose así del distanciamiento y la abstracción con que la filosofía ha tratado estas cuestiones.

Curiosamente, Hayek compartía también ese interés por las cuestiones psicológicas (muy en boga en la Viena en la que pasó su infancia y juventud) y dudó incluso entre dedicarse a la economía o a la psicología. De hecho, la psicología no es en absoluto ajena a la Escuela Austriaca de Economía -que también fue conocida como Escuela Psicológica- porque fundada por Carl Menger en Viena a finales del siglo XIX, consideraba importante los factores psicológicos en la toma de decisiones y creían que las acciones de los individuos estaban determinadas por los que esos individuos creen, saben y desean. No en vano, su célebre teoría del valor se conoce también como "teoría psicológica del valor" 18 .

Hayek pensaba que las percepciones del mundo real son subjetivas, como lo son los objetos de las Ciencias Sociales cuyos actores, además, son siempre individuales. Al enfatizar los aspectos psicológicos y subjetivos de la conducta humana, se necesita la ayuda de las explicaciones psicológicas del comportamiento económico y se insiste en la ignorancia, la incertidumbre y el error debido a nuestras limitaciones psicológicas y cognitivas. Por todo ello, apelaba a la introspección para comprender el comportamiento humano como fuente de conocimiento, ya que los seres humanos compartimos una estructura mental similar, y toma de Max Weber su concepto de verstehen ("comprender desde dentro") como una posible fuente de conocimiento ${ }^{19}$.

${ }^{18}$ En cambio, Shklar escribe en $A$ Life of Learning que había planeado estudiar economía atraída por su rigor, pero que enseguida comprendió que nunca llegaría a ser una economista profesional y se decantó por la filosofía.

19 Por todo esto, la Escuela Austriaca es considerada una de las escuelas precursoras de la economía psicológica tan en boga hoy en día tal como indican R. Arena y L. Larrouy, en "The Role of Psychology in Austrian Economics and Game Theory: Subjectivity and Coordination", GREDEG Working Papers 2015-15, Groupe de REcherche en Droit, Economie, Gestion (GREDEG CNRS), 
Pero dicho esto, para el pensador austriaco, la base económica del liberalismo es fundamental y no concibe una defensa del mismo sin ella. Él quiere dotar a la recuperación del liberalismo de unos fundamentos irrebatibles $\mathrm{y}$, entre ellos, aunque no solo, está la teoría económica. Una teoría económica que no se basa en juicios de valor sino en el conocimiento de los principios y de las leyes de la economía que son las que demuestran, por ejemplo, que el socialismo es imposible. Por eso, la pervivencia de la sociedad liberal depende en gran medida de la existencia y protección de la propiedad privada, la libertad económica, el mercado y la competencia, algo que no parece tan determinante en el pensamiento de Shklar.

\subsection{EI Estado bajo sospecha}

Hayek comparte con Shklar la desconfianza hacia el poder político. Escribe que la limitación eficaz del poder es el problema más importante del orden social porque el gobierno -que es indispensable para protegernos de la coacción y la violencia-, al tener el monopolio de la misma, se convierte a su vez en "la principal amenaza para la libertad individual". Palabras que puede suscribir perfectamente la americana porque en esa sospecha permanente respecto al mal que puede provocar el Estado, coinciden ambos ${ }^{20}$.

Como el Estado es la peor amenaza para la libertad individual y a menudo traiciona a sus ciudadanos debe ser limitado al máximo por todos los medios, aunque también hay que aceptar que todos los gobiernos deben usar la coacción para llevar a cabo sus funciones, con lo cual "un nivel mínimo de miedo existe en cualquier sistema de Derecho". Pero Shklar sigue pensando que no se puede ser libre si estamos atenazados y paralizados por el miedo y el agente que más miedo provoca es el Estado. No en vano, ella llamó a su liberalismo "el liberalismo del miedo" porque creía que lo que debía distinguir a los auténticos liberales era su rechazo de la crueldad (infligir deliberadamente dolor físico y/o emocional para conseguir ciertos fines) y del miedo que ella provoca. La libertad con miedo es imposible. El miedo es la peor condición moral para el individuo y la sociedad: deshumaniza, abate, paraliza y corrompe, y precisamente son los poderosos, sobre todo los que ostentan el poder político, los que lo provocan y extienden puesto que son ellos los que disponen de todos los recursos (militares, policiales, administrativos, tecnológicos...) para infligirlo ${ }^{21}$.

Esa desconfianza hacia el poder que comparten ambos, se basa también en su común escepticismo respecto a las buenas intenciones de los políticos y

\footnotetext{
University of Nice Sophia Antipolis.2015.

${ }^{20}$ Derecho, Legislación y Libertad, una nueva formulación de los principios liberales de la justicia y de la economía política, Unión Editorial, Madrid, 2006, p. 495.

${ }^{21}$ The Liberalism of Fear, op. cit., p. 29. Shklar asegura que los poderosos extienden el miedo siendo crueles: provocando dolor físico y psicológico de forma deliberada para conseguir sus fines.
} 
de los intelectuales. El escepticismo al que ella se adscribe es el escepticismo filosófico de Montaigne y, como ella misma escribe, "a menudo el escepticismo político tiene su raíz en un escepticismo epistemológico en general". Hayek podría suscribir perfectamente estas palabras, aunque -como ya vimos- Shklar creía que el escepticismo hayekiano era selectivo y diferente del suyo. Pero, aunque la naturaleza de su escepticismo sea diferente, ninguno de los dos autores cree en la utopía ni en la posibilidad de construir sociedades perfectas, por eso S. Benhabib ha calificado el liberalismo de la profesora americana como distópico, minimalista y negativo. Un "liberalismo sin ilusiones" porque aquella esperanza de los ilustrados del XVIII de que el desarrollo de la razón y del conocimiento producirá no solo progreso económico y social, sino moral, ha resultado ser una pura ilusión ${ }^{22}$.

Es decir, ninguno de los dos comparte ese liberalismo perfeccionista que sí se encuentra en J. S. Mill o en J. Raz, por ejemplo. Es mucho mejor aceptar a los seres humanos tal y como son y no pretender que colmen nuestras expectativas morales. Además, explicaba Hayek, la sociedad está formada por individuos muy diferentes, con sus distintas escalas de valores contradictorias y complejas, por lo que es imposible que nos pongamos de acuerdo sobre fines y valores. Por eso, es mejor fomentar la tolerancia, la persuasión, el compromiso y la negociación, asumiendo que nunca daremos satisfacción a todos. Como también afirmaba Shklar, tenemos que ser realistas y asumir la imperfección de la condición humana, siendo indulgente con ciertos vicios menores. Además, la búsqueda de la perfección y de la utopía es también una de las fuentes de la crueldad. De alguna manera, para ella las instituciones se apoyan en los vicios de una humanidad irracional, de forma parecida a como Hayek cree que las instituciones responden a la ignorancia humana ${ }^{23}$.

Sin embargo, aunque ella sospecha de la intervención del Estado en la vida de los individuos y escribe que hay que controlar las fuentes públicas del daño, no parece tan preocupada cuando se trata de la intervención del Estado en la economía, lo que la separa profundamente de Hayek que ve también en esa intervención muchos peligros para la libertad. Como es sabido, una de sus tesis más conocidas y debatidas es la que asegura que la intervención estatal en la economía, más allá de ciertos límites, conduce al totalitarismo. "El control de la parte material de la vida da a los gobiernos amplios poderes" y por ello considera que el mercado y la propiedad privada son muy necesarios para limitar el poder

${ }^{22}$ El escepticismo hayekiano se basa en su teoría del conocimiento y en su libro sobre psicología teórica, The Sensory Order. An Inquiry in to the Foundations of Theorethical Psychology, The University of Chicago Press, 1952, trató de demostrar que nuestra ignorancia es constitutiva y que existen límites infranqueables a nuestra racionalidad, y no solo con efectos en el orden de mercado.

${ }^{23}$ Así, por ejemplo, Shklar recuerda a Mandeville cuando dice que hay que tolerar muchos de los vicios ordinarios, los de todos los días, porque pueden tener alguna justificación social o política. Por ejemplo, el esnobismo, fruto de la movilidad social democrática, tiene consecuencias económicas positivas. Véase Ordinary Vices, Harvard University Press, 1984, p. 87 y ss.

Araucaria. Revista Iberoamericana de Filosofia, Política, Humanidades y Relaciones Internacionales, año $21, \mathrm{n}^{\circ} 41$. Primer semestre de 2019. Pp. 37-60. ISSN 1575-6823 e-ISSN 2340-2199 doi: 10.12795/araucaria.2019.i41.02 
político, algo que Shklar no niega, pero no cree que el Estado de Bienestar haya llevado ni vaya a llevar al totalitarismo y critica a los neoliberales por ser tan deterministas en relación a los efectos de la planificación económica ${ }^{24}$.

Lo que ocurre es que, a diferencia de Shklar, Hayek no contempla la posibilidad de que pueda producirse miedo o amenazas serias para la libertad en el mercado. El miedo es político, no económico. En cambio, para ella, las diferencias de poder, riqueza y estatus también intimidan, incluso aunque no exista violencia física. Todo el que tiene poder tiende a abusar de él y existen personajes poderosos que mandan en el mercado, que se hacen con todo tipo de privilegios y extienden su poder económico a la política.

Está claro que el liberalismo de Shklar tiene - como escribe S. Benhabib, "un aroma socialdemócrata". Incluso podría hablarse de un "liberalismo compasivo" por su intención de dar voz a las víctimas, a los oprimidos y a los marginados; a todos aquellos que la sociedad considera "perdedores", los más vulnerables en la economía de mercado, lo que la acerca a la idea de justicia social $^{25}$. En cambio, el economista austriaco se oponía firmemente al concepto de justicia social y a su puesta en práctica porque considera que se trata de una argucia de los grupos de interés para obtener ventajas y privilegios. El papel que cada uno de ellos asigna al Estado para eliminar o reducir la injusticia es claramente distinto.

\subsection{Justicia, injusticia y desventura}

Aunque Judith Shklar considera que la defensa hayekiana del gobierno de la ley no es más que una defensa ideológica de la economía de mercado, lo cierto es que para el pensador austriaco el Estado de Derecho y la soberanía de la ley son también fundamentales para controlar el poder del Estado, salvaguardar los derechos individuales y mantener una sociedad abierta de individuos libres e iguales ante la ley. Lo que es justo es aplicar a todos las mismas normas. La ley, como baluarte de la libertad ha de servir a la justicia y no al gobierno ni a intereses particulares.

Por eso, Hayek - admirador como Shklar de la historia y la cultura política estadounidense- destaca el papel que el poder judicial desempeñó en los Estados Unidos de América definiendo las garantías legales de la libertad individual, y reconoce que las declaraciones de derechos fueron fundamentales para proteger la libertad, la separación de poderes y el imperio de la ley sobre gobernantes y gobernados. La constitución significa "el fundamento de la

${ }^{24}$ La cita de Hayek en Principios de un orden social liberal, Unión Editorial, Madrid, 2010. Shklar se refiere a la planificación en After Utopia, op. cit., p. 241.

25 S. Benhabib, "Judith Shklar's Dystopic Liberalism", en B. Yack, ed., Liberalism without Illusions, The University of Chicago Press, 1996, p. 59. Aunque esta autora recuerda también las críticas de Shklar al paternalismo y su desconfianza respecto a las "ideologías de la solidaridad".

Araucaria. Revista Iberoamericana de Filosofía, Política, Humanidades y Relaciones Internacionales, año $21, \mathrm{n}^{\circ} 41$. Primer semestre de 2019. Pp. 37-60. ISSN 1575-6823 e-ISSN 2340-2199 doi: 10.12795/araucaria.2019.i41.02 
libertad"; es decir, la protección del individuo contra la coacción arbitraria; por todo ello, el liberalismo es constitucionalismo ${ }^{26}$.

Pero es cierto también que en la visión hayekiana del Derecho, la justicia es básicamente una adaptación a nuestra constitutiva ignorancia, no sólo económica, sino también social e incluso moral. La ley es una norma de recta conducta que en la mayoría de los casos es la consecuencia de una evolución espontánea en la que la justicia ha resultado en una adaptación a nuestra ignorancia y que expresa ciertos principios que se encuentran más que se crean. En ese sentido, habla Hayek del sense of justice que poseen los seres humanos y con el que deben concordar las normas de justicia; un sentido de la justicia no innato, sino aprendido en el proceso de la civilización.

Debemos descubrir, entonces, cuál es el prevalente sentido de justicia en cada momento; ese sentido personal e intuitivo de la misma que -advierte-, al ser subjetivo, puede estar equivocado. Así, y de un modo parecido a lo que escribe la pensadora americana, afirma Hayek que las personas pueden no tener claro un criterio absoluto de justicia, pero sí un criterio negativo, por lo que es más probable que puedan determinar lo que no es justo y se pueda así ir eliminando progresivamente lo que ofende nuestro sentido de la justicia ${ }^{27}$

Es decir, Hayek cree que podemos descubrir criterios negativos de justicia que muestren lo que es injusto. Una especie de "test negativo de justicia" que indique en qué dirección debe desarrollarse un sistema jurídico y, aunque hay excepciones, suelen ser normas negativas: prohibiciones de injusticia. Esas normas, de un modo muy kantiano, deben pasar la prueba de universalización. La lucha por eliminar la injusticia puede ser una guía adecuada para hacer un sistema más justo porque solo podemos acercarnos a la justicia por la eliminación progresiva de la injusticia, como ocurre en la ciencia con el acercamiento a lo verdadero por la eliminación de lo falso ${ }^{28}$.

Donde las diferencias entre los dos pensadores liberales se hacen más patentes es en lo que a la justicia distributiva se refiere porque, para Hayek, en un orden espontáneo la situación de cada uno es el resultado de las acciones de multitud de personas que siguen libre y legítimamente su propio interés, con lo que a nadie se le puede adjudicar una responsabilidad concreta. Las consecuencias inintencionadas que inevitablemente se producen en el mercado no son justas o injustas, aunque el deseo humanamente comprensible de buscar responsables nos haga caer en el antropomorfismo y en el abuso lingüístico. Para calificar de justa o injusta una situación ésta tiene que estar sujeta al control humano y hay que poder atribuirle a alguien la responsabilidad, pero una situación que nadie puede cambiar podrá ser buena o mala, pero no justa

\footnotetext{
${ }^{26}$ Véase Los fundamentos de la libertad, Unión Editorial, Madrid, 1998, p. 242.

27 Derecho, Legislación y libertad, op. cit., p. 236.

${ }^{28}$ Ibidem, p. 237. Hayek llama la atención sobre el paralelismo entre su concepción de las normas de justicia y la filosofía de la ciencia de su amigo Karl Popper.
}

Araucaria. Revista Iberoamericana de Filosofia, Política, Humanidades y Relaciones Internacionales, año $21, \mathrm{n}^{\circ} 41$. Primer semestre de 2019. Pp. 37-60. ISSN 1575-6823 e-ISSN 2340-2199 doi: 10.12795/araucaria.2019.i41.02 
o injusta (como tampoco lo puede ser la naturaleza). En definitiva, la justicia social no tiene sentido en un orden espontáneo sino solo en una organización que se rige más por mandatos que por normas generales y abstractas. La justicia es más una cuestión de normas y de procedimientos que de resultados $\mathrm{y}$, aunque "nos sintamos constantemente turbados viendo cómo la vida trata injustamente a las distintas personas", la ley solo debe proteger las expectativas legítimas (las reconocidas legalmente, no cualesquiera). Tenemos que aceptar que algunos sufrirán decepciones inmerecidas porque nunca se podrá eliminar por completo la incertidumbre ${ }^{29}$.

A diferencia del liberalismo más compasivo de la americana, el autor austriaco cree que la justicia no impone a nuestros semejantes el deber de cuidar de nosotros. "El altruismo general es, sin embargo, una concepción carente de sentido. Nadie puede cuidar eficazmente de los extraños. Las responsabilidades que podemos asumir deben ser siempre particulares (...). Uno de los derechos y deberes fundamentales del hombre libre es decidir qué necesidades y qué necesitados se le antojan más importantes", aunque a la vez sostiene que puede ser un deber moral asegurar a los más débiles contra "la extrema desventura". Pero en el fondo, la idea que subyace a la tesis hayekiana y que lo separa de Shklar, es que sí importa cuál es el origen de la injusticia o de la desventura porque uno puede haber sido el responsable de la situación en la que se encuentra y si, a pesar de ello (como sugiere la pensadora americana), hay que remediarla de alguna manera, podemos acabar con la responsabilidad individual $^{30}$.

Sin embargo, del mismo modo que Hayek concede que pueden ser justas o injustas no solo las acciones de los individuos sino también las del gobierno o incluso las acciones concertadas de varias personas u organizaciones, también acepta Shklar que la desigualdad es inevitable y que, aunque la decisión de redistribuir la riqueza, por ejemplo, sea justa, ciertas medidas para aliviar a unos pueden perjudicar a otros que pueden sentirse también injustamente tratados. Además, no queda muy claro cómo compatibilizar la actuación del propio Estado contra la crueldad pública y privada y contra la injusticia pasiva con el respeto por la libertad individual y la separación entre el ámbito público y el privado, sin caer tampoco en el paternalismo bienintencionado que la propia Shklar rechaza en distintas ocasiones ${ }^{31}$. Por todo ello, desde su inveterado escepticismo y en la misma línea que I. Berlin, tenemos que asumir

${ }^{29}$ Derecho, Legislación y Libertad, op. cit., 272.

${ }^{30}$ Ibidem, p. 289 y pp. 224-239 y Los Fundamentos de la libertad, op. cit., p. 114. Resulta curioso el que la tesis de Shklar de que no importa el origen de la injusticia, recuerde a la idea cristiana de la justicia reflejada en algunas parábolas del Nuevo Testamento, aunque ambos autores fueran agnósticos.

${ }^{31}$ Shklar reconoce en J. Bentham a un autor que, al identificar el mal con el dolor, se tomó la crueldad en serio, pero cree también que su benevolencia y su humanitarismo eran en gran medida paternalistas. Véase Ordinary Vices, op. cit., pp. 35-36

Araucaria. Revista Iberoamericana de Filosofia, Política, Humanidades y Relaciones Internacionales, año $21, \mathrm{n}^{\circ} 41$ Primer semestre de 2019. Pp. 37-60. ISSN 1575-6823 e-ISSN 2340-2199 doi: 10.12795/araucaria.2019.i41.02 
que hay valores políticos incompatibles y conflictos irresolubles que en una democracia liberal sólo se pueden tratar de remediar mediante la deliberación y el compromiso.

\subsection{Liberalismo y democracia}

Aunque como escribe Hayek, "la aplicación coherente de los principios liberales conduce a la democracia", ambos pensadores muestran sus recelos respecto al gobierno democrático, puesto que la democracia, si no es liberal y por ello mismo limitada, también puede hacer un uso abusivo del poder. Creer que por someter el poder a control democrático éste no va a abusar es un error ${ }^{32}$.

Hay que salvar la democracia para el liberalismo, pero a ninguno de los dos le gusta las teorías "fuertes" que defienden la democracia participativa o deliberativa; tampoco el republicanismo ni el comunitarismo que ya se estaba desarrollando en su época. Consideran que todas ellas son peligrosas por sus aspiraciones colectivistas herederas del romanticismo político. $\mathrm{Su}$ individualismo liberal hace que desconfíen profundamente de todo tipo de colectivismos. No pueden aceptar ninguna ideología que sacrifique al individuo en el altar de un ideal colectivo. Las lealtades al grupo, la clase o la nación (con sus "orgias de xenofobia", escribe Shklar) son siempre excluyentes porque son sobre todo afectivas y exigen fidelidad. La protección de derechos se refiere siempre a personas concretas e individuales.

Así pues, ambos comparten una visión de la democracia "sin romanticismos". La democracia es un procedimiento para llegar a acuerdos sobre una acción común y su verdadero valor es el de "una precaución sanitaria" capaz de protegernos de cualquier abuso de poder y hacer cambios pacíficos de gobierno. Es más un medio para proteger la libertad que un fin en sí misma. La democracia es un bien instrumental y -en palabras de la profesora americanaforma con el liberalismo "un matrimonio de conveniencia", monógamo, permanente y fiel ${ }^{33}$.

Sin embargo, eso no quiere decir que ella no sea partidaria de la participación democrática, de una ciudadanía responsable y activa; todo lo contrario. Piensa incluso que es positiva y necesaria una educación en las virtudes si queremos luchar contra el vicio cívico que es la indiferencia. Si queremos disfrutar de la democracia sin hacer nada por mantenerla, por comodidad y cobardía, el ideal democrático fracasará. En este sentido ella es mucho más exigente que Hayek

\footnotetext{
${ }^{32}$ Principios de un orden social liberal, $2^{\text {a }}$ ed., Unión editorial, Madrid, 2010, p. 91.

33 The Liberalismo of Fear, op. cit., p. 37. Tampoco es el suyo un "liberalismo de la esperanza", sino "de la memoria"; más bien un liberalismo que trata de controlar daños y evitar el mal; una especie de receta para la supervivencia, un "liberalismo básico o esencial" ("barebone liberalism"). Véase Legalism, op. cit., p. 5.

En cuanto a Hayek, véase Principios de un orden social liberal, op. cit., p. 91, y Derecho, Legislación y Libertad, op, cit., p. 505.
}

Araucaria. Revista Iberoamericana de Filosofí, Politica, Humanidades y Relaciones Internacionales, año $21, \mathrm{n}^{\circ} 41$. Primer semestre de 2019. Pp. 37-60. ISSN 1575-6823 e-ISSN 2340-2199 doi: 10.12795/araucaria.2019.i41.02 
respecto a los deberes ciudadanos. A ella no le basta con cumplir las leyes y abstenerse de hacer el $\mathrm{mal}^{34}$.

Pero, en definitiva, su común experiencia vital y su profundo escepticismo respecto a las posibilidades de la razón y del carácter humano, lleva a ambos a confiar más en las instituciones, la constitución y las leyes que en la virtud de los ciudadanos y, aunque quizás nunca se pueda eliminar el miedo político completamente, son las reglas y las instituciones democráticas las únicas que pueden reducirlo, aunque eso suponga la paradoja de que la propia institución que produce ese miedo deba luchar también contra él. Al final, debemos confiar en que las instituciones que manejan el poder lo controlen y no abusen del mismo.

\subsection{Opciones morales}

El liberalismo de los dos autores rezuma compromiso moral. En ninguno caso (ni siquiera en el liberalismo más economicista de Hayek) existe en sus obras absentismo moral alguno. Hayek, por ejemplo, escribe que el liberalismo es una actitud espiritual, un sistema de principios morales, e incluso habla de la libertad, no solo como principio supremo, sino como credo político o fe. Es el ideal último y soberano del gobierno y de la legislación, el principio moral de la acción política ${ }^{35}$. Además, estos principios -consustanciales a la civilización occidental-, son inamovibles. Por lo tanto, a pesar de la crítica de Shklar en el sentido de que el legalismo hayekiano identifica la moral con la sola obediencia a las reglas, el pensador austriaco iba mucho más allá y afirmaba que la libertad no había funcionado nunca sin hondas creencias morales; por eso, para él, la crisis del liberalismo era también una profunda crisis de valores.

En el caso del liberalismo de la profesora americana, el que toda su obra gire en torno al rechazo absoluto de la crueldad (el summum malum), la centralidad de las víctimas y el reconocimiento de la injusticia como deber cívico, político y democrático supone, desde luego, una clara opción moral. Aunque ella insiste en que no defiende ninguna teoría moral y que no pretende ofrecer un ideal de vida buena sino que únicamente defiende una "moralidad negativa" que trata de evitar el mal más que promover el bien (una moralidad negativa centrada en los vicios a evitar más que en las virtudes a perseguir), lo cierto es que su defensa de la democracia y su rechazo de la crueldad se hace en términos morales, ya que se trata de una exigencia que es fruto del reconocimiento de la dignidad de la persona, en un sentido muy parecido a como lo expresara $\mathrm{Kant}^{36}$. Y ese

\footnotetext{
${ }^{34}$ Los rostros de la injusticia, op. cit., p. 85.

35 "Al igual que todos los principios morales, la libertad exige que se la acepte como valor intrínseco". Los Fundamentos de la libertad, op. cit., p. 101.

${ }^{36}$ Sobre la compatibilidad entre su escepticismo y compromise moral, véase S. Misra, "Doubt and commitment: Justice and Skepticism in Judith Shklar's thought", European Journal of Political
} 
reconocimiento de derechos que sirve para protegerse de los abusos de poder y que no silencia la voz de las víctimas, hace de la democracia la menos cruel de las formas de gobierno.

También Hayek se inspira en el filósofo de Königsberg cuando afirma que la coacción que él rechaza es la que nos impide ser libres porque obliga al individuo a servir a los fines de otro quedándole vedada la posibilidad de perseguir sus propios fines de acuerdo con sus creencias personales; es decir, se le impide forjar su vida de acuerdo con sus ideas ("coercion is evil precisely because it thus eliminates an individual as thinking and valuing person"). Para ambos liberales, el individuo es un fin en sí mismo y nunca debe ser tratado como medio para los fines de otro ${ }^{37}$.

No obstante, a pesar del valor intrínseco que conceden a la libertad, ninguno de los dos afirma que asegure la felicidad. Al contrario, creen que muchas personas le tienen miedo porque -como decía Ortega- hacer nuestra propia vida supone una incesante tarea, una pesada carga y una gran responsabilidad llena de riesgos e incertidumbres que no todo el mundo desea asumir; muchos prefieren la seguridad y la protección a la libertad. De todos modos -nos asegura Shklar- la libertad puede o no hacernos felices, pero sin ella somos ciertamente infelices.

En realidad, ser liberal no sería algo natural, sino algo que requiere de cierta educación que de alguna manera moldee el carácter de los ciudadanos. En Shklar este tema es crucial porque ella cree -como ya advirtiera su admirado Montesquieu al escribir sobre Inglaterra- que el carácter y el gobierno se moldean mutuamente. A ella le interesaba más que a Hayek las cualidades psicológicas de una ciudadanía liberal y creía que había que educar a los ciudadanos sin exigirles virtudes ni heroicidades. Además, el propio marco institucional y la experiencia de los procedimientos justos del Estado de Derecho educan e influyen, aunque sea indirectamente, en el comportamiento de la ciudadanía ${ }^{38}$.

Hayek también creía que las reglas y las instituciones moldean el carácter, condicionan la conducta y fijan hábitos y normas morales indispensables para la libertad, aunque en él hay una separación más tajante entre lo público y lo privado. Ella no hace una separación tan rígida entre el comportamiento público y privado porque nuestras decisiones morales tienen consecuencias también públicas y sociales, como explica en su libro Vicios Ordinarios, y porque lo importante para ella es que haya una frontera que impida invadir el reino privado (aunque esa frontera puede variar al variar históricamente el sentido de la privacidad).

Thought, vol. 15, (1):77-96, 2016.

37 Son conocidas y se han puesto de relieve a menudo, las implicaciones kantianas del pensamiento político de Hayek. Véase, La política de la libertad. Estudio del pensamiento político de F.A. Hayek, $2^{a}$ ed, Unión Editorial, Madrid, 2010, p. 192 y ss.

${ }^{38}$ Shklar dedicó un breve ensayo al pensador bordelés en el que toda su obra se inspira notablemente. Véase Montesquieu, Oxford University Press, 1986.

Araucaria. Revista Iberoamericana de Filosofia, Política, Humanidades y Relaciones Internacionales, año $21, \mathrm{n}^{\circ} 41$. Primer semestre de 2019. Pp. 37-60. ISSN 1575-6823 e-ISSN 2340-2199 doi: 10.12795/araucaria.2019.i41.02 
Por último, frente al anhelo profundamente humano de unidad, seguridad y certeza moral, la realidad es que lo que hay en nuestras sociedades es disenso y desacuerdo sobre fines y valores últimos. De hecho, los ciudadanos de las sociedades contemporáneas pueden estar muy distanciados culturalmente, lo que despierta a menudo el deseo de superar el escepticismo y la duda que esa pluralidad provoca. Shklar rechazaba el comunitarismo de Taylor o Walzer precisamente por considerar que son ideologías del acuerdo en busca de la seguridad cuando esa misma búsqueda del consenso en la mentalidad y los valores comunes, son una fuente de dogmatismo e incluso de fanatismo. Precisamente, el pluralismo y la diversidad son manifestaciones de la libertad y es posible lograr la armonía política por medio de la tolerancia y de la neutralidad del Estado, pues el poder político no debe apoyar nunca ninguna concepción de la vida buena.

También Hayek era plenamente consciente de que era imposible lograr un acuerdo total sobre valores éticos en las sociedades contemporáneas, por eso habla de la necesidad de mantener una atmósfera, un ethos liberal, sin el cual la libertad no duraría mucho. Nadie debe considerarse el juez último de los valores de otra persona y nadie tiene título alguno para impedirle la persecución de fines que desaprobamos: "cada ser humano tiene su propia escala de valores que debemos respetar aun cuando no la aprobemos" y añade que una sociedad que no reconozca que cada individuo tiene derecho a seguir sus preferencias personales, carece de respeto por la dignidad del individuo y desconoce la esencia de la libertad ${ }^{39}$.

\section{Conclusión}

Como hemos visto, tanto Judith Shklar como Friedrich Hayek, experimentaron en el curso de su propia vida la fragilidad de la libertad y de la democracia. Los dos autores vivieron en un contexto histórico en el que la estima por la libertad había decaído profundamente y en el que los valores liberales se vieron amenazados tanto por la izquierda como por la derecha. La historia parecía demostrar que la libertad era un bien precioso, pero raro y delicado que nunca debía darse por supuesto.

La profesora de Harvard afirmaba que el liberalismo es difícil porque es muy exigente. Requiere autocontrol y la disposición a tolerar y convivir con la contradicción, la complejidad, la diversidad y el riesgo, pero nuestra psicología moral o nuestros instintos atávicos - como diría Hayek- nos empujan a todo lo contrario, puesto que la civilización en él y el liberalismo en ella, exigen el sacrificio de ciertos impulsos, pasiones instintivas y conductas

${ }^{39}$ Los fundamentos de la libertad, op. cit, p.114.

Araucaria. Revista Iberoamericana de Filosofía, Política, Humanidades y Relaciones Internacionales, año $21, \mathrm{n}^{\circ} 41$. Primer semestre de 2019. Pp. 37-60. ISSN 1575-6823 e-ISSN 2340-2199 doi: 10.12795/araucaria.2019.i41.02 
innatas arraigadas en los seres humanos; en resumen: "el atavismo basado en emociones primordiales" es más poderoso que los intereses racionales ${ }^{40}$.

Precisamente por haber experimentado y comprendido la dificultad de sostener una sociedad libre, decidieron dedicar su esfuerzo intelectual a recuperar y renovar la tradición liberal a la que ambos se sentían profundamente apegados y a la que Hayek consideraba el mayor legado de la civilización occidental. Una tradición que, aunque más diversa y heterogénea para ella que para él, no dejó nunca de defender como valor moral superior y principio político fundamental la libertad individual que los totalitarismos de ambos signos habían aplastado trágicamente.

En el desempeño de esa labor común, aportan ambos autores nuevas perspectivas, ideas originales e incluso heterodoxas que contribuyen a profundizar en la doctrina liberal del siglo XX y, a pesar de la interpretación que del pensamiento hayekiano hizo en un primer momento la propia Shklar, ambos pensadores se separan de un tipo de liberalismo más sombrío y conservador con el que ninguno de los dos se identificaba porque, aunque se trate en ambos casos de un liberalismo "sin ilusiones", desprovisto de aspiraciones utópicas, "mínimo" o "negativo", lo cierto es que su pensamiento, mucho más inquieto, no los deja estancados en el fatalismo o la resignación ${ }^{41}$. Como el propio Hayek escribiera, el conservador tiene miedo al cambio, a las nuevas ideas, a la evolución y al progreso y a menudo peca de pesimismo y oscurantismo preocupándole más quién gobierna que los límites a ese gobierno. Por el contrario, al liberal no le gusta la quietud ni el estancamiento; tiene una actitud abierta y confiada y es escéptico respecto a las verdades últimas y, desde luego, no es ni puede ser nacionalista; como ideal último, las fronteras nacionales deberían dejar de obstaculizar el libre movimiento de los hombres. Los liberales no tienen miedo a la libertad ${ }^{42}$.

Y no solo eso, su liberalismo tiende a adquirir una orientación práctica y reformista. Como escribe J. Dunn, el liberalismo de Shklar tiene otros objetivos distintos a los de los conservadores y anima al activismo, al cambio y a las reformas. Para ella, por ejemplo, enseñar teoría política era una responsabilidad: una forma de educación política en la que recalcaba que un buen ciudadano liberal es el que lucha por sus derechos, nunca suficientemente respetados, contra la injusticia y a favor de la democracia, puesto que no debemos ser "observadores pasivos de la humillación" ${ }^{43}$.

${ }^{40}$ Derecho, Legislación y Libertad, op. cit., p. 537 y Los Fundamentos de la libertad, op. cit., p. 521-551 y para Shklar, Vicios Ordinarios, op. cit., p. 4.

${ }^{41}$ Aunque algunos comentaristas relacionan a Shklar con la corriente del llamado liberalismo de postguerra; un liberalismo de la prudencia, de la inquietud o del terror, entre los que se contarían R. Aron, I. Berlin o K. Popper. Véase Tavaglione, N. 2013. "Le libéralism de la prudence: contribution à un minimalisme politique", Les ateliers de l'ethique, vol. 8, n. 1: 47-69.

${ }_{42}$ Véase de Hayek su célebre escrito "Por qué no soy conservador", en Los Fundamentos de la libertad, op. cit., pp. 506-521.

${ }^{43}$ Los rostros de la injusticia, op. cit., p. 94. Además, sus últimos escritos, alguno de ellos 
Para el profesor austriaco, también los principios liberales deben servir de guía para solucionar los problemas de nuestro tiempo, sobre todo "cuando los enemigos de la libertad se definen como liberales". Por eso, uno de sus objetivos declarados era luchar por una sociedad abierta influyendo en la vida política de las democracias occidentales a través de lo que él llamaba "la batalla de las ideas", como de hecho así ha sido ${ }^{44}$.

Además, frente a las acusaciones de etnocentrismo y en contra de las tesis relativistas, ambos creían que su liberalismo era universalizable, aunque nunca debiera implementarse por la fuerza. En el caso de Hayek, dado que ha sido la sociedad liberal la que históricamente ha protegido mejor la libertad de hombres y mujeres, otras sociedades deberían imitar sus reglas, valores e instituciones. En el caso de Shklar, cree que puede generarse un consenso universal en torno a su liberalismo porque todo el mundo entiende lo que es sentir miedo, una emoción humana y natural. Es más fácil llegar a un acuerdo sobre la necesidad de reducir o eliminar el miedo que sobre aspiraciones humanas más nobles o la búsqueda del bien. Además, el liberalismo es cosmopolita, por eso "el liberalismo del miedo" se preocupa por todos aquellos que sufren intimidación y abuso en cualquier régimen político. En ese sentido, tiene mucho que ofrecer a las víctimas de la tiranía pues nadie puede de verdad creer que alguien desee la tortura, la violencia o la crueldad que ofende a la humanidad.

En definitiva, creemos que en un mundo en el que -como escribiera Hayek - "es muy posible que la mayor amenaza de la libertad humana surja en el futuro", la comparación del liberalismo de estos dos autores resulta -como escriben F. Boily y N. Boisvert-, no solo "intelectualmente fecunda", sino también altamente provechosa ${ }^{45}$.

aparecidos póstumamente, se ocupan de otro de los temas que a ella siempre (seguramente por su propia experiencia vital), le interesó especialmente: el de los exiliados y refugiados, y su relación con la obligación política y la lealtad.

${ }_{44}$ Derecho, Legislación y Libertad, op. cit., p. 504. Como es sabido, en las transiciones económicas y políticas de la Europa del Este hacia la democracia y la economía de mercado, las alusiones a las tesis hayekianas fueron muy frecuentes. (Véase P. de la Nuez, La política de la libertad. Estudio del pensamiento politico de F.A. Hayek, op, cit. p.201, n.8 ).

${ }^{45}$ F. Boyli y N. Boisvert., "Le liberalism de 1'inquietude: F. Hayek et Judith Shklar", Politique et sociétés, n 333, p. 3-29, 2014.

Hayek se refiere proféticamente a los cambios tecnológicos que crean constantemente nuevas amenazas a la libertad como, por ejemplo, los que posibilitan el control de la mente humana. Véase, Los fundamentos de la libertad, op. cit., p. 297. En cuanto a la tesis de Shklar del párrafo anterior: Liberalism of fear, op. cit., p. 35.

Por otro lado, R. Abbey ha aplicado también algunas tesis de la autora americana a su crítica del comportamiento cruel hacia los animales, que es también una forma de crueldad hacia los seres humanos. Véase, R. Abby, "Exploring Judith Shklar's Liberalism of Fear for Animal Ethics". 


\section{Referencias bibliográficas:}

R. Abby, "Exploring Judith Shklar's Liberalism of Fear for Animal Ethics", 2016.

J. Allen, "The place of negative morality in political theory", Political Theory, vol. 29, n.3. 337-363, 2001.

R. Arena y L. Larrouy, "The Role of Psychology in Austrian Economics and Game Theory: Subjectivity and Coordination”, GREDEG Working Papers 2015-15, Groupe de REcherche en Droit, Economie, Gestion (GREDEG CNRS), University of Nice Sophia Antipolis, 2015.

S. Benhabib, "Biographical Memoirs, Proceedings of the American Philosophical Society", vol. 148, n. 3: 529-534, 2004.

F. Boyli y N. Boisvert, "Le liberalism de 1'inquietude: F. Hayek et Judith Shklar", Politique et sociétés, n 333, 2014: 3-29.

W.A. Galston, "Realism in Political Theory", European Journal of Political Theory, 9 (4): 385-411, 2010.

F. Gauthier, "Faut-il avoir peur du liberalism?", Itaque, Revue de Philosophie de l'Université de Montreal, 16: 53-76, 2015.

J.A. González de Requena, "La inscripción de la violencia y la voz de la víctima. Un replanteamiento de la violencia desde J. Shklar y A. Honneth”, Revista de Filosofía de la Universidad de Costa Rica, LII, 134: 81-92, 2013.

M. Grijalba Uche, "Combatir el olvido de la injusticia desde el liberalismo político: J. Shklar y A. Arteta”, Oxímora Revista Internacional de ética y política, 10: 101-119, 2017.

F.A. Hayek, Camino de servidumbre, Alianza Editorial, Madrid, 1978.

F.A. Hayek, Los Fundamentos de la libertad, Unión Editorial, Madrid, 1988.

F.A Hayek, Derechos, Legislación y libertad, Unión Editorial, Madrid, 2006.

F. A. Hayek, F.A., Principios de un orden social liberal, $2^{\text {a }}$ edición, Unión Editorial, Madrid, 2010.

A. Hess, The political theory of J. Shklar. Exile from exile, Nueva York, Palgrave Macmillan, 2014.

S. Hoffmann, ed., J. Shklar, Redeeming American Political Thought, Chicago: University of Chicago Press, 1998.

S. Hoffmann, ed., J. Shklar, Political Thought and Political Thinkers, Chicago: University of Chicago Press, 1998.

P. Magnette, Judith Shklar. Le libéralisme des opprimés, Editions Michalon, 2006.

S. Misra, "Doubt and commitment: Justice and skepticism in Judith Shklar's thought", 2016.

P. de la Nuez, La politica de la libertad. Estudio del pensamiento político de

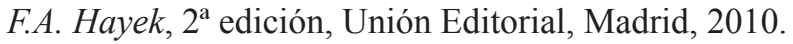


A. Pemberton, Shklar, Justice and injustice, Victimology with a hammer: the challenge of victimology: 42-46, 2015.

F. Ramel, Human Security and Political Philosophy in the Light of Judith Shklar Writing, Human Security Journal, vol 5: 28-34, 2007.

C. Robin, La Peur. Histoire d'une idée politique, Armand Colin, París, 2004.

N.L. Rosenblum (ed), Liberalism and the Moral Life, Harvard University Press, 1989, p.31J. Shklar, After Utopia, Princeton University Press, New Jersey, 1957.

J. Shklar, Legalism. Law, Morals and Political Trials, Cambridge, Massachusetts, Harvard University Press, 1964.

J. Shklar, Ordinary Vices, Cambridge, Massachusetts, Harvard University Press, 1984.

J. Shklar, "The Liberalism of Fear", N.L. Rosenblum, Liberalism and the moral life, Harvard University Press, 1989. (Hay edición española reciente con prólogo de A. Honneth en Herder, Barcelona, 2018).

J. Shklar, American Citizenship, The Taneer Lectures on Human Values, 1989.

J. Shklar, A life of learning, Charles Homer Haskins Lecture, 1989.

J. Shklar, Los rostros de la injusticia, (traducción de Alicia García Ruiz), Herder, Barcelona, 1990.

N. Tavaglione, "Le libéralism de la prudence: contribution à un minimalisme politique", Les ateliers de l'ethique, vol. 8, n. 1: 47-69, 2013.

C. Thiebaut, "Mal, daño y justicia", Azafea. Revista de filosofia, n.7, pp.15-46, Salamanca, 2005.

B. Yack, ed., Liberalism without Illusions, University of Chicago Press, 1996.

S. Young, Political responsibility and Structural Injustice, Lindley Lecture, Universidad de Kansas, 2003.

S. Young, "Avoiding the unavoidable? Judith Shklar's unwilling search for an overlapping consensus", Res Publica: 231-253, 2007. 